\title{
Civil Liability of Obstetrician at the Court of Justice of the State of Rio de Janeiro
}

\author{
Isabel de Fátima Alvim Braga ${ }^{1 *}$, Renata Bastos Mello Pereira ${ }^{2}$ and Laila Zelkcovicz Ertler ${ }^{3}$ \\ ${ }^{1}$ Workdoctor, lawyer and Master in collective health, Oswaldo Cruz Foundation- Human Resources Directory, Brazil \\ ${ }^{2}$ Graduated in Languages, Medical Student at UFRJ, Brazil \\ ${ }^{3}$ Neurosurgeonby UFRJ and Professor of Medicine at UFRJ, Brazil
}

*Correspondingauthor: IsabeldeFátima Alvim Braga,Workdoctor,lawyerand Masterin collectivehealth,OswaldoCruzFoundation-HumanResourcesDirectory, 4365 - Pavilion Figueiredo de Vasconcelos / Room 215 Manguinhos - Rio de Janeiro -RJ, Brazil

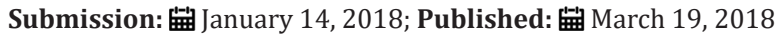

\begin{abstract}
Objectives: To analyze the lawsuits in the area of Obstetrics in the Court of Justice of the State of Rio de Janeiro.

Methods: A search by keyword was carried out on the website of the Court of Justice of Rio de Janeiro with the search term "obstetrics", for lawsuits decisions rendered from $1 / 1 / 2000$ until $12 / 31 / 2015$. We selected only those civil liability lawsuits in which the obstetrician physician was on the passive pole. We found 99 cases in total for the period.

Results: Most of the cases were unfounded. It is important to emphasize the importance of medical experts as an adviser of the magistrate, who is not attached to it's opinion. There has been much discussion about the technical capacity of the experts.

Conclusion: There is a need for more studies contemplating the analysis of judicial lawsuits on the medical topic. It is essential that medical schools approach this area.
\end{abstract}

Keywords: Medical Law; Liability; Medical Liability; Medicine; Law

\section{Introduction}

The earliest known documents on the subject of medical error date from 1790 to $1770 \mathrm{BC}$ and are contained in the Code of Hamurabi [1]. Historically, medical error has been broadly adjudicated in several cultures beyond the above, such as the Law of Moses (1500-600 ac), the Boards of Bognazkeni (1290 ac), Cornelia Law (Roman Empire) and Salic Law (V century), these having been the generators for documentary training contributing to the current bases of the concept of civil responsibility [1].

The Brazilian Federal Constitution (CF) of 1988 assured the citizen the universal right to Health, affirming that this is a right of all and duty of the State [2]. Over the last decades, this legal text is the basis for several legal conflicts aimed at the State as guarantor of the supply of supplies and medical care through the judicial process [3]. Due to the increase in this demand, the National Council of Justice (CNJ) issued Recommendation number 31 of October 30, 2010 , which aims to subsidize judges to they will ensure greater efficiency in the resolution of lawsuits involving health care [4]. The lawsuits in this regard are increasingand are emerging criticism to the ground and legal basis for such decisions $[5,6]$.

Later on, the increased profile of lawsuits reached the issues of medical error and civil liability of physicians and hospital entities, public or private, to seek compensation and civil liability, and more rarely criminal, of these professionals $[7,8]$.

Among the several medical areas, Obstetrics stands out as the specialty with the highest number of procedural litigations, with particular emphasis on childbirth [9]. A number of public documents have been developed to guide the courts and the physicians themselves to deal with these issues, among which the following are the Manual of Ethics in Gynecology and Obstetrics of the Regional Council of Medicine of São Paulo (CREMESP) and Prenatal Care Technical Manual edited by the Health Ministry (MS) $[10,11]$.

The creation of the so-called maternity wards took place in England, the United States, France and Germany during the second half of the 19th century and greatly increased their cleanliness and security [12].

In Brazil, the births of the 1940s to 1960 s were carried out during the transition from home care to hospital. Until the beginning of the 20th century, they were almost without exceptions domiciliary and vaginal delivery. It was in the 1980s, that the Brazilian scenario underwent a major change, with hospitalization at birth [13]. 
The present paper proposes to explore the topic of the medical judicial lawsuits of the Court of Justice of the State of Rio de Janeiro in the scope of the obstetric activity, including the civil responsibility of the physician in these cases and to discuss its consequences on Brazilian jurisprudence.

The general objective of this paper is conduct a data collection on the subject of the lawsuits involving civil liability, involving obstetrics in the TJ-RJ for the years 2000-2015 and as specific objectives we will establish the frequency of lawsuits in obstetrics in the TJ-RJ; check the understanding of the judgment regarding the subject matter in question; check the rate of request for medical expertise by the court; check the question of who is with the doctor in the passive area of the lawsuit; and, finally, analyze the profile of the plaintiffs.

\section{Methodology}

A keyword search was carried out on the website of the Court of Justice of the State of Rio de Janeiro, with the term "obstetrics", for lawsuits with decisions rendered from 1/1/2000 until 12/31/2015. Only those civil liability lawsuits where the obstetrician was on the passive pole were selected. There were 99 cases in total for the period.

The lawsuits against a legal entity and not a private person were not included in the research.

The variables analyzed were:

i. Type of surgery or clinical diagnosis which the cases were about (caesarean delivery, vaginal delivery, curettage, tubal ligation, unidentified procedure, tubal pregnancy, spontaneous abortion).

ii. Figures in the passive pole (medical obstetrician, clinic / hospital, county, state, health insurance).

iii. Active pole figures (patient, patient's spouse, patient's child).

iv. Year of action.

v. Absence or presence of expertise and discussion about it

vi. Proceedings or dismissal of the application.

vii. Judged value for compensation by court.

The data were then tabulated and analyzed in Excel (2007).

The data used were all of public scope and available on the internet.

The authors declare no conflict of interest.

\section{Results}

Found 99 lawsuits. Of these, 4 were excluded because they dealt with administrative law and competition; 2 excluded because they were against the State; 15 against the hospital; 2 against hospital and foundation; 3 against the County; 51 against the health insurance; 1 taxpayer and 1 where the doctor is not defendant but the plaintiff. Figure 1 above shows the distribution of demands from 2000 to 2015 (Figure 1).

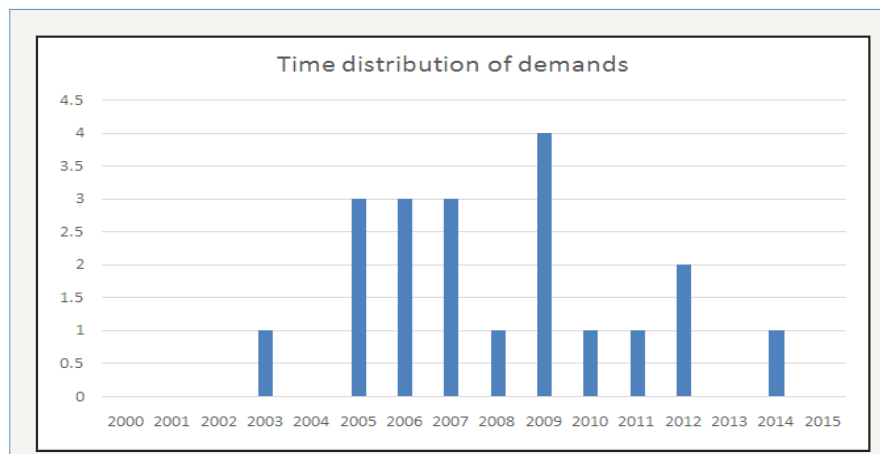

Figure 1 : Time distribution of demands.

Thus, 20 cases have been analyzed.

In $18(90.0 \%)$ cases, the patient was alone on the active pole. Only in $2(10.0 \%)$ cases it did not happen, the active pole was occupied in one case by the child and in another by the patient and the husband, together.

In the passive pole, in most cases, the physician did not appear alone, occurring in only $3(15.0 \%)$ cases. In $2(10.0 \%)$ cases, the lawsuit was against the clinic/ hospital, the health insurance and the doctor. In only 1 (5\%), the lawsuit was filed against the physician and the state of Rio de Janeiro; 1 (5\%) against physician and the County; 1 against the doctor and the plan; 1 doctor, County, hospital/ clinic; 11 (55.0\%) physician and hospital/ clinic.

The procedures/ diagnoses performed by the physicians and that gave rise to the proposed actions were: cesarean delivery (3); curettage (2); tubal pregnancy (2); vaginal delivery (10); tubal ligation (2) and surgical procedure not specified by the data contained in the TJ website (1).

Only $3(15 \%)$ cases were not requested for the expertise. In the following cases: $2(10 \%)$ tubal ligations not performed and 1 due to improper collection of labor. In all cases where there was procedural doubt, the expert was summoned.

Of the $17(85 \%)$ cases in which expertise was requested, 2 ( $10 \%$ of the total) had not yet been performed, in 1 the author did not attend, and 1 was in the stage of aggravation on the expert's ability and capacity. Of those performed, in $8(40 \%)$ of them the expert did not identify a medical error and in 5 he identified an error. In $100 \%$ of the cases where there was an expert, the judge followed the expert.

Of the total cases in progress, 7 (35\%) were without a sentence, 13 (65\%) with sentence in the lower court, 7 (35\%) were unfounded, 4 (20\%) were totally relevant, 2 relevant to the doctor but not to the clinic / hospital.

In the relevant judgments there was a large variation in the arbitrated value, which varied in 2 cases with a value of $\mathrm{R} \$$ $200,000.00$ (two hundred thousand reais), 1 case 25,000.00 (twenty five thousand reais) plus a monthly minimum wage; 1 
case $15,000.00$ (fifteen thousand reais); 1 case 3,500.00 (three thousand and five hundred reais); 1 case 10,230.00 (ten thousand two hundred and thirty reais) and 1 case $60,000.00$ (sixty thousand reais). The vast majority had not even gone unappealable.

There was no process found with these parameters from 2000 to 2002 .

\section{Discussion}

During the period we observed a slight increase in the number of obstetric lawsuits involving physicians. The overwhelming majority of the medical lawsuits of the TJ-RJ occurred with the clinic/ hospital in the passive pole of demand, without the presence of the doctor, a trend that has been modified. The small sample of the number of lawsuits made the tendency to growth only suggested.

One lawsuit was allegedly incorrectly collected in respect of medical fees rather than an error in itself, and was dismissed for lack of evidence of abuse.

Most of the procedures that were litigated were related to childbirth. In fact, most medical articles in obstetrics point to their high rate of complications [14]. The use of partographs is of great importance in obstetrics. Giglio et al. [15] evaluated the quality of hospital care at delivery in a city of Goiás, Goiânia, evidencing that there was a pediatrician in the delivery room in only $30 \%$ of the cases and poor quality of care during labor, with the partogram being used in less than $30 \%$ of deliveries.

We believe that the emphasis given to gynecology and obstetrics in medical error lawsuits is due, in part, to the lack of knowledge of patients and their families about the risks of complications, especially in childbirth. Possibly, the use of an informed consent term or even the clarity of the specialists regarding the risk of the procedures can soften this data.

A study performed at the Obstetrics Service of the Federal University of Juiz de Fora, from 1993 to 1995, evaluated the main perinatal outcomes in high-risk pregnant women. They were: $13.3 \%$ of urinary infections, $12 \%$ of genital infections; $9.33 \%$ of abortions; $6.66 \%$ of fetal death, among others. It is worth noting that postpartum complications occurred in $7.35 \%$ of the patients studied [16]. Thus, with this high rate of complications, it is expected that there will be a great judicial demand of this type.

The childbirth, the great executioner of the aesculapians as regards legal risk, is seen by the population as an event in which there is always a happy ending, and there is an association between a negative outcome and the doctor's incompetence which, despite being perpetrated by the media, is not confirmed.

The expertise demonstrated its importance and the expert's technical capacity was discussed on several occasions.

Most of the cases have already been dismissed. Due to the length of the judicial process, most appeals have not yet been judged and therefore most of the cases have not been resorted to, that is, they still have the possibility of appeals on the sentence already handed down.
In the data of Udelsmann, who analyzed the data of administrative lawsuits on medical ethics from the Chambers of CREMESP, it was evidenced that in all the years studied, which are from 1995 to 2001, obstetrics was the specialty most reported [17].

Spina and Sá carried out similar research to the present, in which they analyzed the profile of civil judicial claims for medical error in Gynecology and Obstetrics in the Judicial Court of the State of São Paulo, a medical specialty that, according to them, has the highest number of lawsuits [18]. An analysis of the first instance cases referenced in 16 judgments of the Court of Justice of the State of São Paulo (TJ-SP) was carried out between June 1, 2013 and May 31, 2014 , and in only $25 \%$ of the cases, the expert confirmed the causal link, generating in all of them the origin of the request. Comparing the indemnity values found in the aforementioned research and the values found in the present study, a tendency of the TJ-RJ to grant in sentences of origin compensations of values smaller than the TJSP, whose values varied between $R \$ 40,000.00$ and $R \$ 466,500.00$. The studies present different temporal moments, which makes this comparison difficult in a strict way because of the possible change of judges and of periods of different economic scenarios. It is evident, however, that the volume of action by medical error in the TJ-SP is indeed larger than in the TJ-RJ.

In the 1990s, Dubay et al. [19] conducted a study that showed that the percentage of obstetricians processed in the United States at least once was $75 \%$. This same study also pointed to the possible and probable consequences of this phenomenon in the field of civil liability insurance.

A study performed by the CRM-SC in ethical lawsuits from 2005 to 2009 found an absolute number of $14.2 \%$ of physicians convicted as belonging to the gynecology and obstetrics specialty, being the specialty with the highest number of condemned persons [20].

Krikor [21] analyzed the profile and ethical-professional infractions of physicians reported in the GO specialty in the State of São Paulo for 10 years, from 1994 to 2004, evidencing that 503 cases $(12.16 \%)$ were related to this sub specialty and involved 781 physicians, with $96.70 \%$ of males and, as in the present article, complaints related to childbirth $(82.33 \%$ of these related to obstetrics). Our data show that the way it is inserted in the system impairs the performance of the obstetrician, since it receives patients from different situations, including those with absence of a physician, whose presence is shown to be crucial for morbidity and mortality rates, this fact is one of the generators of the process increase for this specialty.

Most judges understood that the medical liability of the obstetrician was subjective in nature, and that the obligation is of means not the end, so that he should use all possible means, but he was not obliged to achieve a certain result. Therefore, the doctor was only blamed when proven the evidence of his guilt, namely: negligence, malpractice and/ or recklessness.

Because of the inapplicability of reversing the burden of proof, the courts attach increasing importance to expert evidence, as we 
have seen in the cases above. Although Obstetrics is possibly the medical specialty that has presented the most scientific growth in the last 2 centuries, nevertheless, an adequate and welldone prenatal care to the pregnant woman is one of the greatest guarantors of fetal and maternal perinatal health; in addition to a medical education focused on the physician-patient relationship, which could significantly resolve the number of conflicts $[22,23]$.

In the midst of the evident need for reform in our health system, it is still necessary to remodel the obstetric care model in order to guarantee the safety of the maternal-infant binomial.24

\section{Conclusion}

In spite of the constant media massacre suffered by obstetricians during the last years, in Rio de Janeiro, our study showed that, despite the increase in the legal demand of the obstetrician in the analyzed period, this professional is not yet understood as guilty in most of the cases of outcomes, especially in the case of childbirth.

\section{References}

1. https://jus.com.br/artigos/4288/aspectos-historicos-daresponsabilidade-civil-medica

2. http://www.planalto.gov.br/ccivil_03/constituicao/ constituicaocompilado.htm

3. Gandini JAD, Barione SF, Souza AE (2017) The Judicialization of the Right to Health: obtaining medical care, medicines and therapeutic supplies by judicial means: criteria and experiences. BDjur 2007.

4. http://www.cnj.jus.br/atos-normativos?documento=877

5. Enzweiler RJ, Pereira HV (2011) Medical Law Course. São Paulo, Brazil.

6. Tessler MIB (2010) Justice and Effectiveness in Public Health. Rio de Janeiro.

7. https://jus.com.br/artigos/36673/o-medico-e-a-industria-do-dano

8. http://www.ducatri.com.br/diferencial/rcp.pdf

9. Braga IFA, Ertler LZ (2017) Temporal distribution of medical error in the Court of Justice of Rio Grande doSul. AMRIGS journal, No pleito.

10. CREMESP (2017) Manual of Ethics in Gynecology and Obstetrics.
11. http://bvsms.saude.gov.br/bvs/publicacoes/cd04_11.pdf

12. Martins APV (2005) The science of births: visions of the female body in the constitution of scientific obstetrics in the nineteenth century. Feminist Studies, Florianópolis 13(3): 320.

13. Leister N, Riesco MLG (2013) Birth Assistance: Oral history of women who gave birth in the 1940 s to 1980 s. Texto \& Contexto - Enfermagem, 22 (1): $166-174$.

14. Pereira ALF, de Lima TRL, Schroeter MS, Gouveia M, do Nascimento et al. (2013) Maternal and Neonatal Outcomes of Care in Home Delivery in the municipality of Rio de Janeiro.

15. Giglio MR, França E, Lamounier JA (2011) Evaluation of the quality of normal delivery care. Rev Bras Ginecol Obstet 33(10): 297-304.

16. Araújo J, et al. (1996) High-risk pregnancy: prevalence of maternal-fetal pathologies and complications. Brazilian Journal of Gynecology 106(8): $315-20$

17. Uldersman A (2002) Civil, criminal and ethical liability of physicians. Rev Assoc Med Bras 48(2).

18. Spina VPL, Sá EC (2015) Profile of civil lawsuits for medical error in Gynecology and Obstetrics in the State of São Paulo. Health, Ethics \& Justice 20(1): 15-20.

19. Dubay L, Kaestner R, Waidmann T (2001) Medical malpractice liability and its effect on prenatal care utilization and infant health. J Health Econ 20(4): 591-611.

20. Koeche LG, Cenci I, Bortoluzzi MC, Bonamigo EL (2013) Prevalence of medical error among medical specialties in the cases judged by the Regional Medical Council of the State of Santa Catarina. Catarinense Archive of Medicine 42(4): 45-53.

21. Krikor B (2005) The profile and ethical-professional infractions of denounced physicians practicing gynecology and obstetrics in the state of São Paulo.Institutional Repository UNIFESP. Theses and Dissertations.

22. Marcolin AC (2014) How long will Brazil be known as the cesarean country? Rev Bras Ginecol Obstet 36(7): 283-289.

23. De Souza MA, De Souza TH, Gonçalves AK (2015) Determinants of maternal near miss in an obstetric intensive care unit. Rev Bras Ginecol Obstet 37(11): 498-504.

24. Marcolin AC (2015) Quality and safety: pathways to success of the redesign of the obstetric care model. Rev Bras Ginecol Obstet 37(10): 441-445.
Creative Commons Attribution 4.0 International License

For possible submissions Click Here

\section{Submit Article}

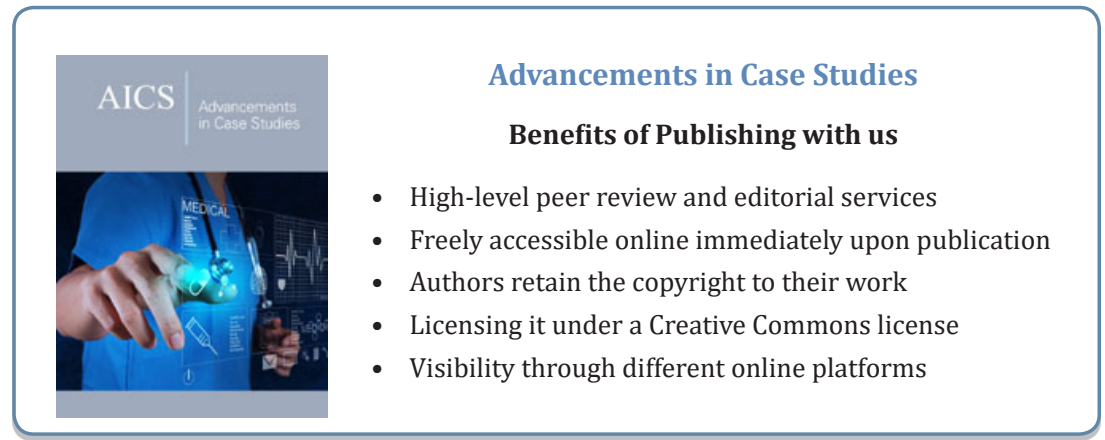

